\title{
La protección del testador vulnerable
}

Antoni Vaquer Aloy

\section{Resumen}

El progresivo envejecimiento de la población y el incremento del número de ancianos que viven solos, ingresados en residencias o atendidos por cuidadores, y en situación de vulnerabilidad, plantea la cuestión de la protección de su libertad de testar ante la posible captación de la voluntad. En este artículo, tras estudiar a efectos de comparación la doctrina de la undue influence del derecho norteamericano, se analizan los mecanismos de protección de que disponen los derechos civiles vigentes en España y cómo los aplica la jurisprudencia.

Palabras clave: Derecho de sucesiones. Testamento. Testador vulnerable. Vicios de la voluntad. Captación.

\begin{abstract}
The progressive ageing of the population and the increasing number of elderly vulnerable people living alone, in nursing homes, or cared by caregivers, raises the question of the protection of their freedom of testation. In this paper, after studying for comparative purposes the American doctrine of undue influence, the author analyses the protection mechanisms available in the civil laws in force in Spain and how case law applies them.
\end{abstract}

Key words: Law of successions. Will. Vulnerable testator. Vices of consent. Undue influence

\section{Sumario}

1. El ejercicio de influencia sobre el causante que lesiona su libertad testamentaria. 2. La undue influence en el derecho norteamericano. 2.1. Cuatro casos ilustrativos. 2.2. Elementos de la undue influence en Estados Unidos. 2.3. Crítica de la doctrina contemporánea. 3. La undue influence en otras jurisdicciones de common law. 4. El testador vulnerable en los derechos civiles españoles. 
4.1. La capacidad para otorgar testamento. 4.2. El dolo. 4.3. La intimidación. 4.4. Los vicios formales del testamento. 4.5. La indignidad sucesoria. 4.6. La prohibición de suceder de los centros asistenciales y de los cuidadores profesionales. A) El derecho catalán. B) El derecho alemán. C) El derecho holandés. D) El derecho de California. 4.7. Estudio de la jurisprudencia española y valoración final.

\section{El ejercicio de influencia sobre el causante que lesiona su libertad testamentaria}

El testador vulnerable es aquella persona de edad avanzada y salud débil que vive solo. Se trata de un sujeto que requiere de una especial protección porque no hay normas específicas de protección en los ordenamientos jurídicos, ya que frente a ellos no hay engaño, no hay intimidación, tampoco error ni violencia, es decir, los vicios tradicionales de la voluntad, sino la captación de la voluntad de manera más o menos sibilina hasta conseguir que forme y exprese una voluntad testamentaria favorable a quien ha ejercido esa influencia. La ausencia de una norma expresa que contemple la influencia indebida sobre el testador aconseja, antes de decidir si estamos ante una laguna normativa de los ordenamientos jurídicos españoles que merece ser colmada legislativamente, recurrir al derecho comparado y tratar con detalle el sistema legal que con más intensidad ha afrontado el tema, y que es el derecho estadounidense. A continuación procede estudiar qué normas, que no son de vicios de la voluntad, tienen como finalidad proteger al testador de posibles injerencias en su voluntad testamentaria, y luego atender a los casos que la jurisprudencia ha resuelto que son susceptibles de ser subsumidos en el supuesto de hecho de influencia indebida o captación de la voluntad del causante. Ello conducirá, por último, a evaluar las respuestas que pueden ofrecer al problema nuestros derechos de sucesiones.

Para evaluar si un testador es vulnerable se han propuesto diversos tests y criterios. Tal vez uno de los más exhaustivos es el estudio encabezado por C. Peisah ${ }^{1}$ que enumera una serie de factores a tomar en consideración: el entorno social del testador (si convive con alguien, si dispone de algún cuidador o de algún buen samaritano), sus circunstancias sociales (si permanece aislado o tiene contacto con familiares además que con quien conviva, si está padeciendo algún conflicto familiar, su grado de dependencia del cuidador), factores físicos (enfermedades, discapacidades sensoriales, problemas de comunicación, trastornos de la personalidad) y las circunstancias en que se ha otorgado el testamento en cuestión. Margaret Singer², por su parte, enumeró

1 C. Peisah et al, "The wills of older people: risk factors for undue influence", 21 International Psychogeriatrics, 2009, p. 7 ss.

2 Margaret Singer, "Undue Influence and Written Documents: Psychological Aspects", 10 Cultic Studies Journal, 1993, p. 19 ss. 
los siguientes factores: el aislamiento del causante, ahuyentando las personas que solían visitarle, leyendo su correo, etc.; forjar la creencia en el causante que el mundo exterior está lleno de peligro y de maldades; fomentar el incremento de su percepción de la situación de dependencia en que se halla; aumentar su sensación de impotencia; provocación de miedos y temores procurar que el causante sea inconsciente de su verdadera situación, todo ello tratándole de situar en una posición similar a un síndrome de Estocolmo.

La importancia del tema resulta de la estadística de personas ancianas que viven solas y que están ingresadas en centros geriátricos. De acuerdo con los datos estadísticos de España que ofrece el Instituto Nacional de Estadística referidos a 2011, más de 270.000 personas viven en residencias de personas mayores, un 68,6\% de las cuales son mujeres ${ }^{1}$. En 2004, en España existían alrededor de1,2 millones de personas de 65 y más años viviendo solas, y en esta situación se encontraban casi el $27 \%$ de los mayores de 84 años, es decir unos 169.000 ancianos, elevándose a 256.000 en la franja de de 80 a 84 años²; los datos de 2011 muestran que En 1.709.186 hogares españoles reside una persona sola de 65 años o más, lo que supone un 8\% más que en 2001, y en tres de cada cuatro de estos hogares reside una mujer ${ }^{3}$. Las solicitudes de atención a la asistencia por personas dependientes mayores de 80 años suman a octubre de 2013 más de 860.000 personas ${ }^{4}$, lo que implica que muchas de ellas están atendidas por un cuidador, sea un profesional o un familiar. A la vez, se estima que el $83 \%$ de los ancianos son propietarios de su vivienda ${ }^{5}$, es decir, que la mayoría dispone de un patrimonio, aunque sea modesto. La soledad en la vejez, acompañada frecuentemente de dolencias más o menos severas, junto a la titularidad de un patrimonio, aunque sea solamente la vivienda y algunos ahorros, pueden despertar la codicia de familiares, cuidadores u otras personas que conozcan o traten con la persona de manera que caigan en la tentación de intentar sugestionarle para que teste a su favor. Se verá con los ejemplos jurisprudenciales que este es un fenómeno, por desgracia, no inhabitual en las sociedades occidentales, España incluida.

\section{La undue influence en el derecho norteamericano}

\subsection{Cuatro casos ilustrativos}

En 1988, Roger Jacobs entabló amistad con Rose Lakatosh, una anciana que vivía sola, salvo ocasionales visitas de su hermana. Durante los siguientes dos años, Jacobs visitó regularmente a Lakatosh una o dos veces por semana, la

\footnotetext{
$1 \mathrm{http}: / /$ www.ine.es/prensa/np777.pdf.

2 http://www.ine.es/revistas/cifraine/0406.pdf.

3 http://www.ine.es/prensa/np824.pdf.

4 Fuente: IMSERSO (http://www.dependencia.imserso.es/InterPresent1/groups/imserso/documents/binario/ im_079778.pdf).

5 http://www.imserso.es/InterPresent1/groups/imserso/documents/binario/presentacionencuestamayores_20.pdf.
} 
acompañaba en coche a sus citas y la ayudaba en sus quehaceres domésticos y encargos. De este modo, pronto Jacobs fue la única persona con la que mantenía contacto. Jacobs le sugirió que le otorgara poderes para poder ocuparse de sus asuntos, a lo que ella accedió. Asimismo otorgó un testamento, mediante un abogado primo segundo de Jacobs, en que dejaba a este la mayor parte de la herencia. Usando el poder, Jacobs se transfirió a él y a su novia, a quien no conocía Lakatosh, 128 mil dólares de la cuenta de esta. En 1990 Lakatosh estaba escuálida y vivía en la inmundicia, incapaz de pagar sus facturas, y finalmente revocó el poder otorgado, pero no el testamento, no falleciendo hasta 1993. El testamento fue anulado por undue influence. ${ }^{6}$

En 1948, el multimillonario por herencia Robert Kaufmann se mudó de Washington a Nueva York para tener independencia y dedicarse a la pintura. Allî conoció a Walter Weiss, de 39 años, a quien contrató luego como asesor fiscal. Kaufmann compró en 1951 una mansión en Manhattan donde se instalaron él y Weiss, dedicándose este a atender la casa, a responder el teléfono y el correo, a procurarle médicos para sus diversas dolencias. En la amplia vida social de Kaufmann se presentaban como pareja mostrándose su amor. Weiss controlaba no solo el dinero sino también los devaneos de Kaufmann con otros hombres. Desde 1951 Kaufmann otorgó diversos testamentos en que progresivamente aumentaba la porción que correspondía a Weiss, el último en 1958; todos ellos iban acompañados de una carta en que Kaufmann expresaba su gratitud hacia Weiss. La familia de Kaufmann desaprobaba la relación, en particular por lo que al control de los negocios familiares se refería, en los que él no estaba interesado, ya que su pasión era el arte. A pesar de ello, Kaufmann concedió poderes preventivos a Weiss por si sufría algún tipo de incapacidad mental y le gratificó en vida con importantes donaciones. La sentencia entendió probado que Weiss animó Kaufmann a modificar su testamento, que fue preparado por un prestigioso despacho de Wall Street sin intervención directa de aquel más que buscando y presentando a un abogado. Impugnado el testamento por undue influence por los familiares de Kaufmann, el tribunal estimó la nulidad. ${ }^{7}$

Fred Strozzi heredó de un hermano Allie en 1987, cuando tenía 86 años, un rancho valorado en un millón de dólares. Strozzi sufría discapacidad física y mental, con una edad mental estimada de 15 o 16 años. El día siguiente al funeral de Allie, las vecinas Betty y Sissy, madre e hija, empezaron a visitarle regularmente. El sobrino de Strozzi, Dean, planteó su incapacitación, a lo que aquel se opuso, llegando finalmente a un acuerdo transaccional por el que

6 Estate of Lakatosh (Pennsylvania, 1995). El caso está extensamente comentado en Carla Spivack, "Why the Testamentary Doctrine of Undue Influence Should Be Abolished", 58 Kansas Law Review, 2009-2010, p. 246 ss, y Dukeminier/Sitkoff/Lindgren, Wills, p. 182 ss.

7 In re Will of Kaufmann (Nueva York, 1964). Los hechos del caso se detallan en extenso en Ray D. Madoff, "Unmasking Undue Influence", 81 Minnessota Law Review, 1997, p. 592 ss; Jeffrey G. Sherman, "Undue Influence and the Homosexual Testator", University of Pittsburg Law Review, 1980-1981, p. 239 ss; Dukeminier/Sitkoff/Lindgren, Wills, p. 191 ss. 
Dean reconocía la capacidad de Fred Strozzi. En noviembre de 1987 Strozzi se lesionó en una caída, e inmediatamente Betty, su marido y Sissy se instalaron en una caravana cerca de su casa, y desde ese momento hasta su muerte de 1992 le cuidaron y realizaron todas las tareas domésticas. En 1988 Strozzi atribuyó un testamento que revocaba el anterior en que nombraba heredero a un vecino y dejaba prácticamente todos sus bienes a Betty y Sissy. El testamento fue anulado a instancias de Dean por undue influence. ${ }^{8}$

Lois J. Frawley enviudó en 1972. En 1976 conoció en una gasolinera a Edward Eugene Gaines, quien entonces estaba casado aunque se divorció en 1978. Dos meses después de conocerse, Gaines-quien había contraído un total de siete matrimonios- se trasladó a casa de Frawley y se convirtieron en pareja de hecho, llegando a intercambiar votos ante un párroco en México. Convivieron hasta la muerte de Frawley en 1980 a causa de un tumor cerebral. La sentencia tiene por probado el carácter duro de Gaines, que solía ir armado, y episodios de riñas con la testadora. El testamento otorgado un año antes en que beneficiaba a Gaines y apartaba a sus hijos fue invalidado sobre la base de undue influence, ya que se reconoció la capacidad para testar pese a su estado de salud pero que su voluntad estaba dominada por Gaines; hay que destacar que ambos testaron a la vez con contenido idéntico. ${ }^{9}$

Albergo la esperanza que el lector considere, como yo, que los cuatro casos son sustancialmente distintos y que, probablemente, no todos ellos merecían la sentencia anuladora del testamento. Por ello, procede a continuación analizar los componentes de la undue influence que ha decantado la jurisprudencia norteamericana y la crítica que le ha formulado la doctrina.

\subsection{Elementos de la undue influence en Estados Unidos}

Hay undue influence cuando la libre voluntad del testador es alterada o suplantada por el acto de un tercero ${ }^{10}$, sin que medie ni engaño -fraud- ni violencia o amenazas -duress-, que constituyen vicios específicos de la voluntad testamentaria ${ }^{11}$. Su función originaria es proteger la autonomía y libertad de elección del testador, invalidando aquellos testamentos que no son fruto de su libérrima voluntad, sino que tal voluntad está dominada por quien ejerce la influencia o sugestión, por lo que, en principio, el remedio va íntimamente ligado a la libertad de testar. ${ }^{12}$

8 In Re Estate of Strozzi (Nuevo Mexico, 1995), consultable en http://www.nmcompcomm.us/nmcases/ NMCA/1995/1995-NMCA-099.pdf.

9 Gaines v Frawley (Texas, 1987), consultable en http://www.leagle.com/decision/19871689739SW2d950_11585.

10 AmmonChase, “Judicial Undue Influence in Probate: A Tongue-in-Cheek Approach to Effectuating Testamentary Intent”, consultable en http://works.bepress.com/ammon_chase/1.

11 Madoff, "Unmasking Undue Influence", p. 579-580.

12 Ronald J. Scalise Jr., "Undue Influence and the Law of Wills: A Comparative Analysis", Duke Journal of Comparative \& International Law, 2008, p. 54-55 
Según Madoff, son cuatro los elementos que la jurisprudencia americana tiene en cuenta para determinar una posible undue influence: a) una relación de confianza entre el testador y quien pretendidamente ejerce la influencia; b) la persona de confianza ha intervenido de alguna manera en la preparación o la redacción del testamento; c) el testador era susceptible de undue influence, lo que supone atender a su edad y condiciones mentales y físicas; d) el causante realiza alguna atribución "no natural" a favor de la persona de confianza, de modo que cuanto más inesperable sea la atribución testamentaria efectuada más probabilidades de undue influence. ${ }^{13}$ Otros elementos que los jueces pueden tomar en consideración son si otras personas distintas de la persona presuntamente influenciadora prestaron asesoramiento al causante y el grado de control de los asuntos económicos y legales de este ejercido por el beneficiado en el testamento ${ }^{14}$. En definitiva, la undue influence conduce al otorgamiento de un testamento con un contenido distinto del que habría tenido de no haber existido la sugestión sobre el causante, y es en este aspecto que guarda una evidente semejanza con el dolo testamentario y la intimidación, aunque no se haya provocado el engaño ni ejercido violencia física y mental, pues ese control de la voluntad puede lograrse igualmente tanto mediante lisonjas como mediante la causación de un temor a desagradar a la persona beneficiada -por ejemplo, que se dejará de atenderle como se venía haciendo- ${ }^{15}$. La prueba de la undue influence es necesariamente indirecta o indiciaria, pues el testador ya no puede prestar su testimonio, y la jurisprudencia americana toma en consideración una pluralidad de criterios, como la relación de confianza existente entre la persona influenciada y la influenciadora -la mayoría son casos de amigos, vecinos o amantes en quienes los testadores han delegado buena parte de sus quehaceres cotidianos, más raramente la doctrina se aplica a familiares-, ${ }^{16}$ la participación de algún modo del beneficiado en la preparación o el otorgamiento del testamento, las condiciones personales del testador -su edad, su estado físico, su dependencia- y el contenido del testamento, es decir, quién ha sido beneficiado y quién no lo ha sido, en particular, si supone un reparto de la riqueza "no natural" porque los beneficiados no pertenecen a la familia del testador sino que la parte del león es para quien ha influenciado o allegados suyos. ${ }^{17}$ Los comentarios al Restatement (Third) of Pro-

\footnotetext{
13 Madoff, "Unmasking Undue Influence", p. 582 ss; Lawrence A. Frolik, "The Biological Roots of the Undue Influence Doctrine: What's Love Got to Do with It?", 57 University of Pittsburgh Law Review, 1996, pp. 850-851, y “The strange interplay of testamentary capacity and the doctrine of undue influence. Are we protecting older testators or overriding individual preferences?", 24 International Journal of Law and Psychiatry, 2001, pp. 258-260; Scalise, "Undue Influence", p. 56 ss; Trent J. Thornley, "The Caring Influence: Beyond Autonomy as the Foundation of Undue Influence", 76 Indiana Law Journal, 1996, p. 517 ss; Jeffrey G. Sherman, "Can Religious Influence Ever Be «Undue» Influence?", 73 Brooklyn Law Review, 2008, pp. 617-618; Irene D. Johnson, "There's a Will, But No Way--Whatever Happened to the Doctrine of Testamentary Freedom and What Can (Should) We Do to Restore It?", 4 Estate Planning and Community Property Law Journal, 2011, p. 113 ss.
}

14 Leslie, "The Myth of Testamentary Freedom", p. 244-245 y 247, nota 45.

15 Madoff, “Unmasking Undue Influence”, p. 575-576; Spivack, "Why the Testamentary Doctrine”, p. 263.

16 No son, por ejemplo, escasas las sentencias que afectan a abogados, señalan Dukeminier/Sitkoff/Lindgren, Wills, p. 186-190 y 198 ss.

17 Madoff, “Unmasking Undue Influence”, p. 583 ss; Sherman, “Can Religious Influence”, p. 619. 
perty: Wills \& Other Donative Transfers, por su parte, subrayan la existencia de una presunción favorable a la undue influence cuando el causante era susceptible de ella, el beneficiado tuvo la oportunidad de ejercerla y se observa un resultado explicable por esta influencia, ${ }^{18}$ y se refieren a las circunstancias sospechosas en el otorgamiento del testamento que son síntomas de esa sugestión indebida, como si el testamento se preparó con sigilo o supone un cambio radical con el testamento anterior sin que hayan concurrido hechos que puedan explicar esa mutación. ${ }^{19}$

La undue influence no presupone necesariamente la falta de capacidad natural del testador, pues entonces el testamento carecería ya de validez; basta con que sea susceptible de la captación de su voluntad ${ }^{20}$, pero en la práctica es frecuente que se combinen la alegación de la influencia indebida y de la falta de capacidad natural del testador, ya sea para asegurar un resultado favorable a la impugnación del testamento al disponer de dos vías argumentales, ya sea para reforzar la impresión de la debilidad del causante ante la sugestión empleada, con la idea de que a menor capacidad de obrar mayor susceptibilidad de ser influenciada la persona. ${ }^{21}$

\subsection{Crítica de la doctrina contemporánea}

La doctrina viene criticando la aplicación judicial de la undue influence de forma casi monolítica, porque en vez de servir de arma protectora de la libertad de testar, no infrecuentemente acaba desembocando en un ataque frontal contra ella. Madoff ${ }^{22}$ considera que supone denegar la libertad de testar a quienes se apartan de las normas judicialmente asentadas de reparto de la riqueza a la muerte, en particular la norma no escrita de que los bienes deben ir a parar a los familiares. Esta es la crítica más común en un sistema en que no hay legítimas para los hijos: el testador que se aparta de los cánones de la atribución de su herencia a sus descendientes o, en su defecto, los parientes más cercanos, corre el riesgo de ver impugnado el testamento y, en la eventualidad de que triunfe la impugnación, la herencia se reparte intestada igualitariamente con lo que su planificación mortis causa simplemente se esfuma. Scalise señala que es una ironía que el estándar del carácter natural de la ordenación de la

18 Restatement (Third) of Property: Wills \& other Donative Transfers, St Paul, Mn, 2003, § 8.3, comentario e), p. 158.

19 ld., comentario h), p. 161.Véase, también, John C.P. Goldberg, Robert H. Sitkoff, "Torts and Estates: Remedying Wrongful Interference with Inheritance”, 65 Stanford Law Review, 2013, p. 345 ss.

20 Robert H. Sitkoff, "Trusts and Estates: Implementing Freedom of Disposition", 58 St. Louis University Law Journal, 2014, p.646: "The line between indelicate but lawful persuasion on the one hand, and undue influence and duress on the other, can be difficult to assess in posthumous litigation. Distinguishing between the peculiarities of old age and true mental infirmity can be equally vexing. Judges and juries may be tempted to find undue influence or incapacity if the testator's dispositions seem unfair or Unnatural".

21 Sherman, "Can Religious Influence", p. 619; Frolik, "The strange interplay", especialmente p. 263 ss, y "The Biological Roots", pp. 844-845; Kenneth I. Schulman, Carole A. Cohen, Felice C. Kirsh, lan M. Hull, Pamela R. Champine, "Assessment of Testamentary Capacity and Vulnerability to Undue Influence", American Journal of Psychiatry, mayo 2007, p. 722 ss.

22 Madoff, “Unmasking Undue Influence”, p. 576. 
sucesión sea su acomodación a las reglas de la sucesión intestada que son precisamente las que quiso evitar que se aplicaran quien otorgó testamento $^{23}$, llegándose incluso a cuestionar la oportunidad de testar a favor de quien no es destinatario natural de la herencia por la alta probabilidad de que el testamento acabe por ser ineficaz. ${ }^{24}$ La vaguedad ${ }^{25}$ de los elementos de la undue influence permite decisiones ideológicas de los tribunales, ${ }^{26}$ que siempre son proclives a favorecer a la familia clásica ${ }^{27}$ frente a otro tipo de relaciones afectivas, ${ }^{28}$ ya sean fuera de la familia convencional o interraciales. ${ }^{29}$

\section{La undue influence en otras jurisdicciones de common law}

La doctrina de la undue influencese originó, como es lógico, en Inglaterra, desde donde se expandió por las colonias inglesas, aunque en ningún otro lugar ha alcanzado los resultados estadounidenses que se acaban de presentar sucintamente. Apunta Kerridge que el derecho inglés no ha conseguido tejer un sistema que verdaderamente proteja a los testadores vulnerables, entendiendo por tales a las personas ancianas de salud frágil solteras o viudas, sin hijos y sin contacto regular con sus familiares. ${ }^{30}$ La undue influence procede de los

23 Scalise, "Undue Influence", p. 58.

24 Johnson, "There is a Will", p. 117.

25 O borroso ("fuzzy") y nebuloso, en palabras de John C.P. Goldberg, Robert. H. Sitkoff, "Torts and Estates: Remedying Wrongful Interference with Inheritance", 65 Stanford Law Review, 2013, p. 344.

26 Spivack, "Why the Testamentary Doctrine of Undue Influence", pp. 276-277

27 Frances H. Foster, "The Family Paradigm of Inheritance Law", 80 North Carolina Law Review, 2001, p. 210: "in practice, judges and juries manipulate mental capacity doctrines such as "undue influence" and "insane delusion" to reach results more in accord with the family paradigm"; Leslie, "The Myth of Testamentary Freedom", p. 236 ("courts impose and enforce this moral duty to family through the covert manipulation of doctrine [of undue influence]") y $p$. 243 ss bajo la rúbrica "manipulation of doctrine to ensure family preference"; E. Gary Spitko, "Gone But Not Conforming: Protecting the Abhorrent Testator from Majoritarian Cultural Norms Through Minority-Culture Arbitration", 49 Case Western Reserve Law Review, 1999, p. 280: "the very standards aimed at ensuring testamentary freedom risk the testamentary freedom of a nontraditional testator who willingly executes an estate plan that fails to conform to societal norms, namely those preferring the legal spouse and close blood relations to all other potential beneficiaries"; Frolik, "Biological Roots", pp. 843-844: "In recognition of the nearly universal desire to favor descendants, and in particular, children, the law has created the doctrine of undue influence to overturn gifts to nonlineal descendants, second spouses, lovers, friends, loyal housekeepers, and the like, and, relying on intestacy laws, direct the inheritance to the testator's descendants (...) the doctrine's continued application reflects its alignment with some of society's most deeply held values about obligations, family, property, and inheritance. These values, in turn, issue forth from our psychological natures which derive from our common genetic heritage"; Goldberg/Sitkoff, "Torts and Estates", p. 246: "Safeguarding freedom of disposition requires the court to invalidate a disposition that was not volitional because it was procured by undue influence. But openness to circumstantial evidence facilitates the bringing of strike suits by disgruntled family members whom the decedent truly meant to exclude. Moreover, the plasticity and vagueness of the undue influence concept allow judges and juries leeway to rewrite the decedent's estate plan in accordance with their own views of fairness and morality".

28 Joseph W. deFuria Jr, "Testamentary Gifts Resulting from Meretricious Relationships: Undue Influence or Natural Beneficence?”, 64 Notre Dame Law Review, 1989,p. 200 ss.

29 Susanna L. Blumenthal, "The Deviance of the Will: Policing the Bounds of Testamentary Freedom in Nineteenth-Century America”, 119 Harvard Law Review, 2006, p. 960 ss; Bernie D. Jones, "“Righteous Fathers," "Vulnerable Old Men," and "Degraded Creatures": Southern Justices on Miscegenation in the Antebellum Will Contest", 40 Tulsa Law Review, 2005, p. 699; y Kevin Noble Maillard, "The Color of Testamentary Freedom", 62 Southern Methodist University Law Review, 2009, p. 1783 ss, que analizan la suerte de los testamentos en que blancos instituian a sus esclavas negras o a la descendencia nacida de relaciones sexuales con las esclavas en los Estados Unidos del siglo XIX, en que la undue influence constituía uno de los motivos habituales de impugnación.

30 Roger Kerridge, "Wills Made in Suspicious Circumstances: The Problem of the Vulnerable Testator", 59 Cambridge Law Journal, 2000, p. 310. En la p. 315 aporta la noticia periodística de una mujer especializada en conseguir que testadores viudos ancianos otorgaran testamentos ológrafos a favor de su hija. Hay que advertir una diferencia con el derecho norteamericano: si el testamento se anula por razón de falta de capacidad, se abre la sucesión intestada, pero si la causa de nulidad es el dolo o, eventualmente, la undue influence, la herencia se defiere en constructive trust a favor de quien realmente pretendía beneficiar el causante ( $p .330$ ), lo que provoca mayores 
tribunales de equidad, que no resolvían aplicando estrictamente la ley, lo que se señala que constituye el origen de la actual porosidad de la doctrina en los Estados Unidos, en casos en que testadores "débiles" otorgaban testamentos en que no se favorecía a los parientes más allegados. ${ }^{31}$ Ninguno de los diversos tribunales competentes en materias sucesorias se mostró capaz de deslindar la undue influence del dolo o de la intimidación entrado el siglo XIX. Solo lentamente fue asentándose la idea, aun sin la necesaria delimitación con aquellos vicios de la voluntad, que la idea central radica en el otorgamiento de un testamento en que alguien ha conseguido que se exprese una voluntad que no es la real del testador. ${ }^{32}$ Por su parte, los tribunales de probate (common law) aplicaban unos requerimientos mucho más severos que ocasionaban que solo raramente la impugnación fuera exitosa al exigirse una prueba directa de coerción y no considerar suficiente la simple oportunidad de influir en el testador. ${ }^{33}$ Pese a la fusión más adelante de los tribunales de common law y de equity, no se han notado cambios en la jurisprudencia ${ }^{34}$ y en Inglaterra la undue influence no ha alcanzado el hiperdesarrollo norteamericano, al haberse trazado unos requisitos de prueba más estrictos, ${ }^{35}$ habiéndose circunscrito especialmente a casos en que ha existido un abuso de confianza, como cuando el beneficiado por el testamento era el asesor legal del testador. ${ }^{36}$

Los tribunales de los Estados de common law de Canadá se han adherido esencialmente a la concepción estricta de la undue influence propia de la jurisprudencia inglesa, exigiendo una prueba cumplida de coerción y solo ampliando algo el espectro si se dan "circunstancias sospechosas" de que ha podido

dificultades en el triunfo de la acción, en contraste con el otro lado del Atlántico, pues en los Estados Unidos los jueces son más proclives a estimarla.

31 Spivack, "Why the Testamentary Doctrine of Undue Influence", p. 250 ss. La autora reporta algunos casos de testadores que prefirieron sus amantes, incluso aunque planearan casarse con ellas, a sus hijos.

32 Por ejemplo, Wingrove $v$. Wingrove (1885): "To be undue influence in the eyes of the law there must be -to sum it up in a word-coercion. It must not be a case in which a person has been induced by means such as I have suggested to you to come to a conclusion that he or she make a will in a particular person's favour, because if the testator has only been persuaded or induced by considerations which you may condemn, really and truly to intend to give his property to another, though you may disapprove of the act, yet it is strictly legitimate in the sense of its being legal. It is only when the will of the person who becomes a testator is coerced in to doing that which he or she does not desire to do that it is undue influence. The coercion may of course be of different kinds, it may be in the grossest form, such as actual confinement or violence, or a person in the last days or hours of life may have become so weak and feeble, that a very little pressure will be sufficient to bring about the desired result, and it may even be that the mere talking to him at that stage of illness and pressing something upon him may so fatigue the brain, that the sick person may be induced, for quiteness' sake, to do anything. This would equally be coercion, though not actual violence (citado por Spivack, "Why the Testamentary Doctrine of Undue Influence", p. 260; el fragment puede encontrarse también en http://swarb.co.uk/wingrove-v-wingrove-1885/).

33 Pauline Ridge, "Equitable Undue Influence and Wills", 120 Law Quarterly Review, 2004, p. 621; Fiona R. Burns, "Reforming Testamentary Undue Influence in Canadian and English Law", 29 Dalhousie Law Journal, 2006, pp. 457-458.

34 Roger Kerridge, Parry and Clark The Law of Succession, London, 2002 11 , 5-30, p. 78.

35 Fiona R. Burns, "Elders and Testamentary Undue Influence in Australia", 28 University of New South Wales Law Journal, 2005, pp. 148-149; Scalise, “Undue Influence”, pp. 50-51.

36 Wintle v. Nye (1959), que comenta extensamente Kerridge, "Wills Made in Suspicious Circumstances", p. 315 ss, constituye un buen ejemplo. Se trataba del testamento otorgado por una señora soltera y rica a favor de su abogado, preparado por este y en el que actuaron como testigos empleados suyos, en que solo dejaba una muy modesta pensión periódica a su hermana y a su prima, con quien había convivido largos años. El testamento fue anulado a instancias del hermano de la prima, en el que fue el primer caso de anulación de un testamento en un proceso dirigido por quien no era letrado, el teniente coronel retirado Alfred Wintle. 
sugestionarse al testador. ${ }^{37}$ Un ejemplo de este distinto enfoque en comparación con los vecinos de sur estadounidenses lo proporciona el caso Vout $v$ Hay (1995) en que el Tribunal Supremo casa la sentencia en apelación del tribunal de Ontario. ${ }^{38}$ Clarence Hay era un granjero soltero que a los 78 años revocó su testamento, en que repartía la herencia entre su hermano y sobrinos, otorgando uno de nuevo en que el grueso de la herencia pasaba a Sandra Vout, una chica de 24 años que le ayudaba en la granja y con quien no consta que mantuviera relaciones sexuales. El testamento fue preparado por las secretarias del abogado que gestionaba los asuntos de los padres de Vout. Hay murió asesinado tres años más tarde por un hombre que confesó el crimen sin involucrar a Vout. El Tribunal Supremo no consideró la concurrencia de undue influence y dio por válido el testamento.

Por lo que a Australia se refiere, durante el siglo XIX los tribunales eran mucho más flexibles en el análisis de las circunstancias de cada caso, sin que fuera imprescindible la prueba de la coercion si de los demás elementos se desprendía la debilidad de la voluntad del testador y su influenciabilidad. Progresivamente, sin embargo, se fue adoptando el criterio inglés más restrictivo, lo que llevó a que la undue influence dejara de ser alegada como único motivo de impugnación de la validez del testamento, soliendo ir acompañando la objeción a la capacidad testamentaria. De ahí que se proponga en la doctrina una reformulación de la doctrina con el fin de adecuarla a una sociedad con una población más envejecida. ${ }^{39}$

\section{El testador vulnerable en los derechos civiles españoles}

La Sra Matilde, soltera y sin hijos, murió en Lleida el año 2010 a los 87 años. Entre 1958 y 1979 había vivido en París donde trabajaba como asistenta doméstica, volviendo en vacaciones de verano y navidad para pasar unos días con su familia. Una vez jubilada, se instaló definitivamente en la ciudad de Lleida en la que había sido vivienda de la familia, un inmueble en mal estado y objeto de especulación inmobiliaria, donde vivía sola con síntomas, según el relato fáctico de la sentencia, encuadrables dentro del síndrome de Diógenes. En noviembre de 2004 otorgó testamento notarial a favor del abogado con quien mantenía una relación profesional desde 1995 y que era prácticamente la única persona con quien se relacionaba. La sentencia del juzgado de primera instancia núm. 5 de Lleida de 21 de noviembre de 2011 declara la nulidad del testamento por falta de capacidad testamentaria sobre la base de la enfermedad psíquica (alzheimer y trastorno delirante paranoide) que sufría, sentencia confirmada por la AP Lleida de 4.4.2013. ${ }^{40}$

37 Burns, "Reforming Testamentary Undue Influence in Canadian and English Law", p. 460 ss.

$38 \mathrm{http}: / /$ scc-csc.lexum.com/decisia-scc-csc/scc-csc/scc-csc/en/item/1273/index.do.

39Burns, "Elders and Testamentary Undue Influence in Australia", passim.

40 Id Cendoj: 25120370022013100142. 
Este caso se hubiera resuelto en el derecho norteamericano, e incluso en el derecho inglés, aplicando la doctrina de la undue influence, por la relación de confianza existente entre abogado y cliente. Ninguno de los derechos civiles españoles recoge una figura similar. Esto no significa, sin embargo, que el testador vulnerable quede completamente desprotegido ante la posible captación de su voluntad por parte de personas que desean obtener alguna atribución mortis causa. Antes al contrario, existen una multiplicidad de expedientes que, funcionalmente, pueden desempeñar un papel similar. ${ }^{41}$

\subsection{La capacidad para otorgar testamento}

Los ordenamientos civiles españoles exigen para otorgar válidamente testamento que el causante se halle en el goce de sus facultades mentales, es decir, que tenga capacidad natural en el preciso momento de testar (art. $663.2^{\circ} \mathrm{CC}$, 421-4 CCCat, 408 CFA, ley 184 FN). La falta de capacidad natural determina la nulidad del testamento, y esta es la primera vía que pueden tomar los jueces y tribunales ante la captación de la voluntad del testador vulnerable. La sentencia con que se inicia este capítulo constituye un ejemplo, pero pueden citarse otros. Por ejemplo, en la STSJ Cataluña 1.7.1999,42 la testadora, mientras estaba ingresada en el hospital, testó a favor de una sobrina con sustitución vulgar a favor de su descendencia. El tribunal consideró nulo el testamento sobre la base de la enfermedad mental -alzheimer-que le impedía gobernarse por sí misma. Por su parte, la STS 5.11.200943 declara nulo por falta de capacidad de la testadora un testamento notarial en que se alegó la captación de la voluntad de la testadora por uno de sus hijos, recordando que "[e]l Notario debe apreciar la capacidad del testador, pero este no es un juicio definitivo, puesto que la jurisprudencia de esta Sala ha venido manteniendo la posibilidad de destruir la presunción de capacidad que se deriva de las afirmaciones notariales, porque se trata de una presunción iuris tantum que admite prueba en contrario". Y en la SAP Burgos 21.12.200644la testadora otorgó testamento ológrafo en la habitación del hospital en que se hallaba ingresada en presencia de varias personas, entre las que se contaba el principal beneficiado en el testamento, que la sentencia anula por falta de "cabal juicio". ${ }^{45}$ Es cierto que

41 Scalise, "Undue Influence", p. 60 ss, realiza precisamente un esfuerzo por señalar las similaridades funcionales entre la undue influence norteamericana y otras figuras propias de los derechos civiles continentales.

42 Westlaw-aranzadi RJ 200018030.

43RJ 2010/84.

44 JUR 2007/326.

45 Razona así la sentencia: "Del análisis de la actividad probatoria obrante en la causa, y tanto por las circunstancias objetivas y subjetivas concurrentes en el momento del otorgamiento, como por la naturaleza de la relación con el beneficiario, como por el contenido del propio testamento, se considera que la acusante no se encontraba en su "cabal juicio», a los efectos de poder comprender la importancia y las consecuencias de sus propias acciones y que la permitiera decidirse libremente sobre sus propias determinaciones con la adecuada capacidad natural de entender y querer y de expresar su voluntad libre y conscientemente, ajustada al propio querer, y entender interno sin intermediación e influencias externas, y con la adecuada normalidad de conciencia que le permitiese comprender la importancia y consecuencias de las propias acciones y decidir libremente". 
existe una presunción de capacidad natural del testador y que esta presunción es especialmente reforzada cuando el testamento es notarial, pero no es menos cierto que cuando se proporciona prueba suficiente nuestros tribunales no vacilan en declarar la nulidad del testamento. ${ }^{46}$ El testador vulnerable no es necesariamente una persona carente de capacidad natural para testar, ${ }^{47}$ pero sí que su voluntad expresada, por la influencia recibida, no es espontánea y completamente propia, por lo que la vía de la nulidad del testamento por falta de capacidad testamentaria si no es técnicamente la más precisa, sí que permite lograr el resultado deseado de proteger la libertad de testar privando de eficacia al testamento o a sus cláusulas que no son fiel reflejo de la verdadera intención del causante. ${ }^{48}$ Se ha visto ya cómo también en las jurisdicciones de common law la undue influence se fusiona las más de las veces con la alegación de la falta de capacidad para testar, ${ }^{49}$ por lo que por esta vía pueden resolverse los casos en los que exista convicción de la ausencia de condiciones volitivas para otorgar el testamento.

\subsection{El dolo}

Aunque no tiene como objeto materia sucesoria sino una donación, el dolo como vicio invalidante de la voluntad ha sido aplicado recientemente a los actos de disposición lucrativos. Se trata de la STS 28.9.2011, ${ }^{50}$ que declara la nulidad de una donación por dolo del donatario, hijo de la donante, quien habría preparado el otorgamiento de una escritura de donación de varios inmuebles a él y a los nietos de la donante, cuando ella estaba dispuesta a la donación de un único inmueble, poniendo el énfasis en la relación de dependencia emocional de la donante con su hijo, y concluyendo que es necesario que "el consentimiento del donante sea meditado y reflexivo y no prestado, como ocurrió en el caso, bajo un estado emocional provocado por la situación deliberadamente creada por el demandado para arrancar dicho consentimiento de forma irreflexiva". Es evidente que la misma ratio puede aplicarse

46 Por citar solo dos ejemplos recientes, STS 26.4.2008, RJ 2680, o STSJ Cataluña 17.10.2011, Id Cendoj: 0801931001201110007.

47 Lo reconoció ya la STS 30.6.1944, RJ 948: "Que para llegar a declaración de nulidad del testamento de que se trata, no se funda el fallo recurrido en la falta de capacidad del otorgante, pues si bien afirma en el tercero de sus considerandos que tal capacidad estaba alterada, deprimida, notoriamente disminuida a causa de una extrema debilidad y sufrimientos físicos y morales que privaban al testador de aptitud para rechazar imposiciones, no sienta dicho considerando, ni ningún otro de la sentencia, la afirmación de que en el momento de otorgar el acto de última voluntad fuese don Joaquín de S. incapaz para testar".

48 Así lo ha entendido Spivack, "Why the Testamentary Doctrine of Undue Influence", p. 291-292: "Turning to the goals of undue influence, a properly administered capacity test can efficiently protect the elderly from exploitation". En esta línea, se ha propuesto importar la figura del notariado latino a Estados Unidos por Nicole M. Reina, "Protecting Testamentary Freedom in the United States by Introducing into Law the Concept of the French Notaire", New York Law School Law Review, 2002-2003, p. 797 ss.

49 Tomando inspiración del derecho holandés (art. 4:55(2) Código civil) y del derecho inglés (Court of Protection Rules 2007), el autor sudafricano J.C. Sonnekus, "Freedom of Testaron and the Ageing Testator", en Reid/De Waal/ Zimmermann (ed.), Exploring the Law of Succession, p. $95 \mathrm{ss,} \mathrm{propone} \mathrm{para} \mathrm{las} \mathrm{personas} \mathrm{ancianas} \mathrm{el} \mathrm{otorgamiento}$ de testamento con la intervención de la autoridad judicial, con la finalidad de tratar de frenar los intentos de captación de la voluntad del causante.

50 RJ 6586. 
a los testamentos, teniendo en cuenta que, como ya se ha indicado, el dolo figura entre los vicios de la voluntad testamentaria (art. 673 CC -"dolo o fraude"-, 422-1.1 (testamento) y 422-2.1 (disposiciones testamentarias) CCCat -"engaño"-, 424.2 CFA -"engaño"-).

Luego en el apartado 4.7 se toman en consideración otras sentencias en que se ha alegado el dolo testamentario, para ver con una perspectiva más amplia cómo la jurisprudencia española valora ciertas conductas urdidas para captar la voluntad del testador.

\subsection{La intimidación}

Son escasísimas las sentencias que han anulado un testamento con base en este vicio de la voluntad. Una que ha hecho uso en particular de la opción de la intimidación es la STSJ Cataluña 8.4.2010. ${ }^{51}$ En el supuesto, la testadora, de edad avanzada y salud frágil, testó a favor de la hija con quien convivía, alterando su anterior testamento, que había otorgado sin que lo supiera esta hija retomando la orientación de un testamento previo a la convivencia con ella. Argumenta la sentencia que "cabe presumir fundada y racionalmente que si la Sra. Vidal había obligado a su nonagenaria madre, que siempre había mantenido la misma línea de sucesión, a cambiar un testamento en el año 2000, como ella misma se había encargado de explicar en vida a sus allegados y el cual, no obstante el control al que estaba sometida, logró volver a cambiar en el año 2001, mostrándose satisfecha con dicho cambio, el nuevo testamento tuvo el mismo origen, -la presión ejercida por la hija beneficiada- ya que ninguna circunstancia distinta se había producido -ni se intentó explicar siquiera por las demandadas- que motivasen el cambio de la que siempre había sido su voluntad, lo que viene corroborado por las anómalas circunstancias en que se produjo el otorgamiento del nuevo testamento en la clínica Platón en marzo del 2002, con discusiones previas entre madre e hija y el aislamiento al que, una vez otorgado éste, estuvo sometida la causante por su hija y su nieta", más aun cuando se estima probado que se apartó "a la causante de su entorno y sometiéndola a una estrecha vigilancia que incluía escuchas detrás de la puerta y obligación de la cuidadora de explicar el contenido de las conversaciones que tenía con la viuda de su hijo, madre de los actores, cuando iba a visitarla hasta el momento en que se impidieron incluso dichas visitas". De este modo, se observa como un supuesto de la captación de la voluntad de la causante puede reconducirse, por las peculiaridades del supuesto -la violencia moral y la presión, más que la sugestión, de acuerdo con los hechos probados, parece evidente- por el cauce de la nulidad por intimidación. Otro 
tanto sucedió con la causante en la SAP Guipúzcoa 10.9.2002,52 en que se tuvo por probado que, desde que se trasladó a vivir con su hija y yerno, estos "la despreciaban e insultaban, teniendo un miedo permanente de que la pegaran". Y parece oportuno recordar que la intimidación no tiene necesariamente que provenir de la persona beneficiada por la disposición testamentaria para que sea determinante de la nulidad.

\subsection{Los vicios formales del testamento}

Otra solución que en ocasiones ha propugnado la jurisprudencia ante testamentos otorgados por personas vulnerables ha consistido en apurar la exigencia de requisitos formales del testamento para, una vez entendido que no se cumplían, decretar la nulidad del testamento por infracción de formalidades, que es causa de nulidad en los art. 687 CC, 422-1.1 CCCat, 423.1.a) y b) CFA y ley 206 FN.

La primera sentencia que cabe traer a colación es la STSJ Cataluña 7.1.1993, ${ }^{53}$ que deniega la protocolización de un pretendido testamento ológrafo, firmado por la causante y dos testigos y datado, en atención a la cantidad de palabras añadidas y tachadas y a la envergadura de los párrafos entrerrenglonados. Arguye el tribunal que "[e]l documento del folio 217, por su carácter fragmentario, por el cúmulo de tachaduras y enmiendas que presenta a pesar de su brevedad y por otras circunstancias extrínsecas que analizan las sentencias de instancia más parece un simple borrador o esbozo que una verdadera y definitiva disposición de última voluntad; a pesar de que aparezca firmado y con una fecha «estampada en diferente momento escritural que el resto del texto», según palabras textuales de los peritos". Por ello, "[l]a sentencia recurrida no infringe la doctrina jurisprudencial sucintamente expuesta en el fundamento jurídico precedente, pues las tachaduras, enmiendas, entrerrenglonados y añadidos que presenta el manuscrito y que no han sido salvadas son de tal extensión e importancia que lo invalidan como testamento ológrafo". Siendo esto cierto, la clave, a mi entender, es que el pretendido testamento ológrafo lo había otorgado una causante de edad avanzada siendo el principal beneficiado la persona que la sentencia denomina "hombre de confianza" de la testadora.

La segunda sentencia que conviene referenciar es la STS 10.6.2005..$^{54} \mathrm{El}$ testador, de 88 años de edad y afectado por una patología grave, como consecuencia de la cual falleció pocos días más tarde, testó en forma de testamento en peligro de muerte. La sentencia anula el testamento por defecto de forma por no haberse acreditado la imposibilidad de otorgar un testamento notarial ante el hecho de que el testador residía en Madrid. Curiosamente, el TS niega que en el caso se hubiera probado la concurrencia de dolo. Pero lo cierto es 
que el testador se hallaba ingresado en un centro geriátrico, que los cinco testigos que intervinieron en el otorgamiento eran empleados de dicho centro y que la heredera instituida era la administradora de dicho centro geriátrico. En cualquier caso, y pese a la intuición de la posible captación de la voluntad del causante a la vista de las circunstancias del otorgamiento, el testamento acaba siendo declarado nulo, aunque sea acudiendo al incumplimiento de las formalidades testamentarias.

\subsection{La indignidad sucesoria}

Lo anterior nos conduce a otro expediente al que cabe acudir para obtener la ineficacia de un testamento ante la sospecha de la posible captación de la voluntad del testador vulnerable: la indignidad sucesoria. La indignidad puede contemplarse también desde el punto de vista de la libertad de testar. ${ }^{55}$ Constituye una sanción privada consistente en la privación de su eficacia a las atribuciones a favor de quienes han cometido una determinada ofensa contra el testador. Entre las causas de indignidad se cuentan manipulaciones de la voluntad testamentaria tales como la inducción a otorgar testamento o pacto sucesorio, o a revocarlo, así como impedir testar o revocar el testamento, aparte de la destrucción, alteración u ocultación del testamento (art. $756.5^{\circ}$ y $6^{\circ}$ CC, 412 -3.g y h CCCat, 318.f y g CFA), ${ }^{56}$ sea el favorecido el indigno u otra persona distinta. ${ }^{57}$ Todos estos hechos suponen un evidente ataque frontal a la libertad testamentaria. Sin embargo, debe tenerse en cuenta que, como sanción, tiene carácter personalísimo, y en la medida en que sus causas son de interpretación restrictiva ${ }^{58}$, no afecta a los descendientes del indigno, que incluso ocuparán la posición de este en los derechos sucesorios legales como la legítima (art. 761 CC, 451-3.2 CCCat, 336.1 CFA -sustitución legal-).

55 Reinhard Zimmermann, "Erbunwürdigkeit - Die Entwicklung eines Rechtsinstituts im Spiegel europäischer Kodifikationen”, en Festschrift für Helmut Koziol, Wien, 2010, p. 463 ss. Como dice José Pérez de Vargas Muñoz, La indignidad sucesoria en el Código civil español, Madrid, 1997, p. 101, "el fundamento de esta causa de indignidad -como la del $756.6^{\circ} \mathrm{Cc}$ - está en que constituye un verdadero atentado a la libertad del testador". Por su parte, Luis Díez-Picazo, Antonio Gullón, Sistema de Derecho Civil, IV, Madrid, 2012, p. 35, señalan que la ratio del precepto es "castigar toda conducta contraria a la libertad del testador para expresar su última voluntad". Finalmente, María Paz García Rubio, Marta Otero Crespo, "Capacidad, incapacidad e indignidad para suceder", en $\mathrm{M}^{\mathrm{a}}$ del Carmen Gete-Alonso y Calera (dir.), Tratado de sucesiones, I, Cizur Menor, 2011, p. 260, mencionan la "protección de la integridad de la voluntad testamentaria".

56 Pedro Del Pozo, Antoni Vaquer, Esteve Bosch, Derecho de sucesiones, $2^{\mathrm{a}}$ ed., Madrid-Barcelona-Buenos AiresSao Paulo, p. 449-450; Fernando Gómez Pomar, art. 412-3, en Egea Fernández/Ferrer Riba (dir.), Comentaris al llibre quart, p. 102 ss; Josep Llobet Aguado, en M.C Gete-Alonso y Calera, J. Llobet Aguado, J. Solé Resina, M. Ysàs Solanes, Derecho de sucesiones, p. 46-48.

57 Así también Pérez de Vargas, La indignidad sucesoria, p. 101.

58 Véase STS 11.2.1946, RJ 121; SAP Zaragoza 8.11.2007, AC 2008/273; SAP León 28.12.2009, JUR 2010/107904; y, para el derecho catalán, Roca i Trias, en Lluís Puig i Ferriol, Encarna Roca i Trias, Institucions de dret civil de Catalunya, III, Valencia, 2009, p. 85; Del Pozo/Vaquer/Bosch, Derecho de sucesiones, p. 450; para el derecho aragonés, José Antonio Serrano García, en Jesús Delgado Echeverría (dir.), Manual de derecho civil aragonés, Zaragoza, $2012^{4}$, p. 522. Con todo, téngase en cuenta los matices que introducen García Rubio/Otero Crespo, "Capacidad, incapacidad e indignidad para suceder", p. 250-251. 


\subsection{La prohibición de suceder de los centros asistenciales y de los cuidadores profesionales}

La jurisprudencia, tanto española como de otros países, pone de manifiesto que un supuesto de hecho especialmente problemático es el de los testamentos otorgados por personas mayores a favor de sus cuidadores, por el riesgo o sospecha de que estos puedan haber captado la voluntad del testador dirigiendo su voluntad testamentaria a la satisfacción de sus intereses propios. Son diversos los mecanismos que se proponen en el derecho comparado para subvenir a estas situaciones.

\section{A) El derecho catalán}

El nuevo derecho catalán de sucesiones ha introducido un mecanismo específico de protección de la libertad de testar de un concreto grupo de testadores especialmente vulnerables. Se trata de las personas que están ingresadas en centros o residencias asistenciales o geriátricas o bajo las atenciones de cuidadores profesionales. De acuerdo con el art. 412-5.2 CCCat, "[l]as personas físicas o jurídicas y los cuidadores que dependen de las mismas que hayan prestado servicios asistenciales, residenciales o de naturaleza análoga al causante, en virtud de una relación contractual, solo pueden ser favorecidos en la sucesión de este si es ordenada en testamento notarial abierto o en pacto sucesorio". Es decir, los testadores que deseen favorecer mortis causa a los cuidadores profesionales o a los responsables o empleados de los centros asistenciales en que se hallan ingresados deben acudir necesariamente al testamento notarial. La limitación concierne únicamente al cuidador profesional, es decir, al que se dedica laboralmente a cambio de un sueldo o remuneración al cuidado de personas que necesitan asistencia, sin afectar a los familiares que realicen esas mismas tareas sin contraprestación. El legislador considera que en la medida en que el notario debe valorar la capacidad del testador (art. 42 1 7 CCCat, como también los art. 685.1, 696 y 707.4 CC ${ }^{59}$ ), podrá ejercer un control de capacidad que permita desvelar si su voluntad no es completamente libre sino que ha sido captada y modulada por el cuidador ${ }^{60}$. Por ello mismo,

\footnotetext{
59 Recientemente véase Juan J. Rivas Martínez, art. 695, en Código civil comentado, II, p. 358 ss; Beatriz Verdera Izquierdo, "La incapacidad y la discapacidad al otorgar testamento", en $\mathrm{M}^{\mathrm{a}}$ del Carmen García Garnica (dir.), Estudios sobre dependencia y discapacidad, Cizur Menor, 2011, p. 122-123.

60 Del Pozo/Vaquer/Bosch, Derecho de sucesiones, p. 447-448; Fernando Gómez Pomar, art. 412-5, en Joan Egea, Josep Ferrer (dir.), Comentaris al llibre quart del Codi Civil de Catalunya, Barcelona, 2012, p. 123-124; Martín Garrido Melero, Derecho de sucesiones, Madrid-Barcelona-Buenos Aires, 2010, p. 642. La importancia del rol preventivo de la función notarial lo enfatiza la SAP Cáceres 31.5.2011, JUR 237305, cuando argumenta lo siguiente: "La Juzgadora del conjunto de las pruebas testificales, valoradas según las reglas de la sana crítica, ha otorgado especial significación a los testigos presenciales que acompañaron a la testadora en el momento de otorgar el testamento abierto ante el Notario, según los cuales, la madre se encontraba muy segura de lo que quería, le manifestó al Notario que quería que todo fuera para su hija, siendo el fedatario público quien informó que debía respetar la legitima de su otro hijo. A luz de dichas pruebas y la intervención del Notario, que no hubiera permitido ninguna influencia en la testadora, de tal intensidad que mutara su voluntad, no se estima acreditado la existencia de dolo o fraude en dicho otorgamiento del testamento abierto, ni se puede inferir del hecho de que la hija se hubiera ocupado de las atenciones de su madre en los últimos años de su vida, por más que los testigos propuestos
} 
esta norma goza de un valor indiciario y programático, pues aunque no quepa su aplicación analógica por tratarse de una norma prohibitiva, si marca una tendencia o aviso para otras profesiones que puedan desempeñar otra actividad que entrañe una relación de confianza y de dependencia con el testador, además de los supuestos ya conocidos del cuidador profesional y del confesor, como enfermeras, médicos o abogados, por citar algunos ejemplos. No existe ninguna norma similar en el resto de derechos civiles españoles.

Esta norma se ubica sistemáticamente junto a las causas de inhabilidad sucesoria, y puede compartir con ellas la misma ratio, esto es, tratar de impedir la influencia ${ }^{61}$ sobre el testador, de notarios, tutores o miembros de órdenes religiosas $^{62}$ (art. 752-755 CC, 412-5.1 CCCat); funcionaría, pues, como una norma preventiva ante el riesgo de la capacidad de influencia sobre el testador para beneficiarse de la última voluntad del causante. ${ }^{63}$ García Rubio señala que, en ordenamientos como el francés italiano o español, "la solución ex post derivada de la posible anulación del testamento por vicios del consentimiento u otras figuras negociales es muy restringida ${ }^{64}$ y se completa con una solución ex ante que impide en todo caso la eficacia de la disposición a favor de determinadas personas que, a juicio del testador, por su peculiar relación con el testador pueden influir en su voluntad de modo pernicioso". ${ }^{65}$ No obstante, los respectivos efectos jurídicos son distintos a los de la inhabilidad sucesoria. Las causas de inhabilidad permiten la declaración de ineficacia de las disposiciones testamentarias a favor de las personas inhábiles a instancia de cualquier persona que pueda resultar beneficiada por dicha declaración (art. 412-6 CCCat). En cambio, los directores o empleados o los cuidadores profesionales no se listan entre las personas susceptibles de ser inhábiles. Lo

por la parte actora insistan en las pésimas relaciones entre la madre y la hija antes de que ésta se hiciera cargo de su madre" (énfasis añadido).

61 Francisco de Asís Sancho Rebullida, art. 752, en Ministerio de Justicia, Comentario, I, p. 1856: "Ia ratio iuris de esta norma estriba en impedir la captación de la voluntad del testador por parte de su confesor en una situación de especial vulnerabilidad"; Albaladejo, Curso de derecho civil, V, p. 91; Lacruz Berdejo/Rams Albesa, Elementos de derecho civil V, Sucesiones, p. 59; Carlos Martínez de Aguirre, en Pérez Álvarez (coord.), Derecho de sucesiones, p. 85; Del Pozo/Vaquer/Bosch, Derecho de sucesiones, p. 447.

$62 \mathrm{En}$ el derecho norteamericano hay casos de undue influence relativos a ministros de iglesias. Uno de los más destacados es In Re Estate of Maheras Oklahoma, 1995). La testadora, que murió en 1991 a los 96 años de edad, había tenido problemas de alcoholismo hasta que en 1980 entró en contacto con la Primera Iglesia Baptista y su pastor en Bartlesville. Los miembros de la iglesia y el pastor le proporcionaron diversa ayuda. Participó en un cursillo sobre otorgamiento de testamentos, que no completó. El pastor le proporcionó la guía que al respecto se había elaborado y procedió a inventariar sus bienes, y le puso en contacto con un abogado miembro de la misma iglesia. Este abogado preparó el testamento, en que la beneficiaria era la Primera Iglesia Baptista, siendo todos los testigos intervinientes feligreses de la misma. Un sobrino de la testadora impugnó el testamento, que fue anulado al apreciarse undue influence. La sentencia puede consultarse en http://yourlawprof.com/22w/law13/maheras.htm, y Spivack, "Why the Testamentary Doctrine of Undue Influence", p. 284, la comenta. Nótese que el testamento fue otorgado mucho antes del fallecimiento.

63 Juan José López Burniol, art. 412-5, en Encarna Roca Trias (coord. gen.), Sucesiones, Madrid, 2012, p. 81.

64 Como se comprobará infra en el apartado 4.6 de este capítulo.

65 María Paz García Rubio, art. 752, en A. Cañizares Laso, P. de Pablo Contreras, J. Orduña Moreno, R. Valpuesta Fernández (dir.), Código Civil comentado, II, Cizur Menor, 2011, p. 616. La autora continúa: "Estas personas son excluidas por ley de la sucesión voluntaria del causante, por lo que algunos autores las consideran verdaderas prohibiciones de suceder. No es, sin embargo, una figura estructuralmente necesaria en todos los ordenamientos de nuestro entorno jurídico, donde esa función de control de la voluntad testamentaria se hace mayormente a través de otras instituciones protectoras de la integridad de la voluntad del autor del acto como la undue influence del common law o las guten Sitten del § BGB". 
que hace el derecho catalán es prohibir directamente que se beneficie en un testamento no notarial a los cuidadores profesionales. Hay que notar que en la sociedad actual hay muchos más cuidadores que confesores, con lo que en definitiva no se está sino actualizando una norma de larga tradición en nuestros ordenamientos jurídicos.

\section{B) El derecho alemán}

En el derecho alemán, el $§ 14$ de la HeimGesetz prohíbe expresamente las atribuciones testamentarias a los dueños, directores y empleados de residencias geriátricas realizadas por quienes residen en ellas, ${ }^{66}$ así como a sus familiares,${ }^{67}$ solo se excepcionan las que tengan escaso valo ${ }^{68}$ Se trata de una verdadera prohibición ${ }^{69}$ de suceder que afecta a estas personas en razón de su profesión y de la vulnerabilidad de las personas a quien la norma persigue proteger. Si a pesar de la prohibición se otorga un testamento que contiene una tal cláusula, esa cláusula es radicalmente nula. La constitucionalidad de esta norma ha sido refrendada por el Tribunal Constitucional alemán en sentencia de 3.7.1998, ${ }^{70}$ al considerar que cumple la función de proteger a personas vulnerables y a la libertad de testar que reconoce el $\S 14$ de la Constitución alemana (derecho a la propiedad y a la herencia). ${ }^{71}$ El Tribunal Supremo Federal alemán ha matizado, sin embargo, en sentencia de 26.10.2011, ${ }^{72}$ que el $\S$ 14 no impide que el propietario de una residencia geriátrica sea instituido en un testamento cuyo otorgamiento ignora, pues en tal caso no hay injerencia en la libertad testamentaria del causante. La jurisprudencia alemana ha entendido que si el favorecido prueba su desconocimiento del otorgamiento del testamento no entra en juego la prohibición, pues en tal caso no ha podido afectar la libertad testamentaria de la persona residente. La doctrina alemana ya había propuesto una interpretación restrictiva del conocimiento por el titular del centro geriátrico del otorgamiento del testamento, requiriendo que fuera objetivo y no meramente subjetivo, ${ }^{73}$ de modo que si la voluntad del causante es realmente la de instituir a la persona afectada por la prohibición

66 Y también por terceros si se realizan en interés o por cuenta de quien está ingresado en la residencia geriátrica. 67 Leipold, Erbrecht, p. 87, Rn 242, citando una sentencia del OLG Frankfurt de 2001.

68 "Dem Trägerist es untersagt, sich von oder zugunsten von Bewohnerinnen und Bewohnernoder den Bewerberinnen und Bewerbernumeinen Heimplatz Geld- oder geldwerte Leistungenüber das nach $\S 5$ vereinbarte Entgelthin aus versprechen oder gewähren zulassen", dice su párrafo (1)). Una selección de pronunciamientos judiciales relativos al $\S 14$ HeimG puede verse en Wolfgang Edenhofer, en Palandt, BGB, $70^{\text {th }}$ ed., München, 2011, § 1937, Rn 13.

69 Markus Plantholz, § 14, en Utz Krahmer, Ronald Richter (ed.), Heimgesetz. Lehr- und Praxiskommentar, BadenBaden, $2005^{2}$, p. 175.

70 http://www.bundesverfassungsgericht.de/entscheidungen/rk19980703_1bvr043498.html.

71 Scalise, "Undue Influence”, p. 68; Gunter Crö man, Saschalffland, Rainer Mangels, HeimG Taschen-Kommentar, Hannover, 2002, pp. 317-318.

72 http://juris.bundesgerichtshof.de/cgi-bin/rechtsprechung/document.py?Gericht=bgh\&Art=en\&sid=72a483ae8f6c5efff8bb70a983b89953\&nr=58335\&pos=0\&anz=1.

73 Hartmut Münzel, "Heimbewohnerund Testierfreiheit - Zur Anwendbarkeit des § 14 । HeimG aufletztwillige Verfügungen", Neue Juristische Wochenschrift, 1997, p. 113. 
sea posible hallar un resquicio que lo permita pese a la inicial rigidez de la norma prohibitiva.

\section{C) El derecho holandés}

El nuevo Código civil holandés (BW) contiene dos normas distintas, dentro del capítulo dedicado a las inhabilidades para suceder por testamento, que merecen la atención. Se trata de los dos apartados del art. 4:59, con el matiz que introduce el art. 4:60. De acuerdo con el primer apartado del art. 4:59, los profesionales de la salud, en particular los de la salud mental, que han asistido al testador durante su última enfermedad no pueden ser beneficiados en el testamento otorgado durante dicha enfermedad o asistencia. A continuación, el apartado 2 añade la inhabilidad para suceder de quien explota comercialmente o dirige un centro geriátrico o psiquiátrico cuando el testamento ha sido otorgado durante el ingreso. El legislador procura de este modo delimitar la relación causal entre el ingreso y el otorgamiento del testamento, no impidiendo la institución o el legado fuera del momento idóneo para la captación de la voluntad. El art. 4:60 excepciona la compensación de los servicios prestados, teniendo en cuenta el patrimonio del causante y el valor de los servicios prestados, y cuando el beneficiario es un pariente dentro del cuarto grado por consanguinidad o afinidad o el cónyuge. La sanción en caso de incurrir en inhabilidad es la nulidad de la disposición testamentaria, de acuerdo con el art. 4:60.

\section{D) El derecho de California}

Otra norma interesante se encuentra en la section 21350 del California Probate Code, ya que establece la invalidez, a salvo de lo que dispone la section 21351, de cualquier transmisión a título lucrativo -lo que incluye al testamento- a favor de (apartado 6) su cuidador (care custodian) realizada por un adulto dependiente. Las excepciones que enumera la section 21351 son: (a) que el beneficiario sea un pariente, un cohabitante o una pareja de hecho registrada, o sea, los cuidadores no profesionales; (b) que el testamento -u otro acto jurídico- haya sido revisado por un abogado independiente que haya advertido al disponente de la naturaleza y los efectos del actoque se propone otorgar, que haya evaluado si el otorgante está determinado por dolo, amenazas, intimidación o influencia indebida, y firma y entrega al disponente un certificado original que acredite lo anterior conforme al formulario que contiene en el mismo Probate Code.

Carmel L. Bosco, viuda y sin hijos, ordenó un trust el 28.9.1991, que luego modificó hasta siete veces, siendo objeto de litigio la última de estas modifi- 
caciones. James Foley y su novia Ann Erman, quien previamente había estado casada con un sobrino de Bosco, eran amigos desde hacía tiempo de la testadora, y la estuvieron cuidando durante su última enfermedad. La sentencia tiene por probado que Foley hacía la compra para Bosco y que Erman estaba todo el día con ella, cuidándola, cocinándole la comida, atendiendo a su higiene, incluso la íntima, haciendo la colada y suministrándole sus medicinas, y en ningún momento hace mención de que sus familiares -una hermana y sobrinos- le prestaran otros cuidados. La séptima modificación del trust decidida por Bosco tres días antes de su fallecimientosuponía que Foley y Erman eran beneficiarios del trust por partes iguales. La sentencia entiende que Foley y Erman eran care custodians y que, en consecuencia, la modificación del trust era nula en aplicación de la section2 1350. La prueba de que Bosco era feliz con Foley y Erman y estaba bien atendida carece de valor para el tribunal, porque los beneficiarios no lograron probar la ausencia de undue influence. ${ }^{74}$

La aplicación práctica de una norma razonable puede llevar a resultados nefastos. La sentencia en el caso Bernard v Foley puede ser un ejemplo de ello, pues penaliza al buen samaritano, por supuesto si, atendiendo a los hechos que el tribunal da por acreditados, no consta que se empujara a la causante a ordenar la modificación del trust o, en nuestros términos, a otorgar un testamento que beneficie al samaritano. No debe haber problema en beneficiar a quien se preocupa en procurar las atenciones necesarias para la ancianidad si tal es la verdadera voluntad, aunque sea postergando a familiares que desde la lejanía se desentienden de los cuidados que requieren los mayores. ${ }^{75}$ De ahí que, criticando esta sentencia, se haya propuesto modificar la definición de legal custodian para incluir en tal concepto únicamente a quienes desarrollan profesionalmente dicha actividad, en la línea del Código Civil de Cataluña o de la HeimGesetz alemana. ${ }^{76}$ De otro modo el testador está limitado para recompensar a sus vecinos altruistas si tal es su deseo, lo que contraviene su libertad testamentaria si su voluntad se ha formado sin vicios.

\footnotetext{
74 Bernard v Foley (California, 2005), consultable en http://cases.laws.com/california/california-bernard-v-foley6-30-05-ca2-3.

75 Sobre los derechos sucesorios vinculados al cuidado del testador en el derecho comparado véase mi trabajo "Desheredación por falta de relación familiar y libertad de testar: a propósito de la nueva causa de desheredación del art. 451-17.e del Código Civil de Cataluña", en José M. de la Cuesta (coord.) y otros, Homenaje al Profesor Carlos Vattier Fuenzalida, Cizur Menor, 2013, p. 1160 ss. La atención de los ancianos de salud débil dentro de la familia extensa permite liberar recursos públicos que pueden destinarse a otras finalidades, pero obviamente plantea el problema de cómo el cuidador ve recompensados sus esfuerzos. Véase, al respecto, con distintas propuestas, Izuahara, Housing, care and inheritance, especialmente p. 110 ss; Hendrik Hartog, Someday All This Will Be Yours. A History of Inheritance and Old Age, Cambridge, Massachussets-Londres, 2012; Brian Sloan, Informal Carers and Private Law, Oxford-Portland, 2013, p. 91 ss.

76 Kirsten M. Kwasneski, "The Danger of a Label: How the Legal Interpretation of "Care Custodian" Can Frustrate a Testator's Wish to Make a Gift to a Personal Friend", 36 Golden Gate University Law Review, 2010, p. 269 ss, en particular p. 283 ss.
} 


\subsection{Estudio de la jurisprudencia española y valoración final}

Los mecanismos que se acaban de analizar en los subapartados anteriores ponen de manifiesto que los derechos civiles españoles gozan de suficientes medios para proteger la voluntad del testador vulnerable. No es, por ello, necesario introducir ningún nuevo vicio de la voluntad como la influencia indebida. Como se ha notado, la posible captación de la voluntad del causante va ligada las más de las veces a la duda sobre la capacidad testamentaria, aparte de que existen vicios ya consagrados como el dolo o la intimidación que no dejan resquicio teórico por donde intentar deslizar una sugestión del causante que quede incólume. Además, el derecho catalán ofrece una norma específicamente concebida para los cuidadores profesionales, más flexible que las equivalentes californiana y alemana, ${ }^{77}$ pues permite que el testador realice atribuciones mortis causa a favor del cuidador o del centro asistencial si esa es realmente su voluntad, con lo que se procura respetar al máximo la libertad de $\operatorname{testar}^{78}$. Además, debe ser posible una interpretación extensiva del precepto, para los supuestos en que el cuidador profesional no sea el beneficiario directo, pero sí lo sea un allegado suyo, en atención a la finalidad que persigue el legislador.

Otra cosa es cómo se aplique en la práctica, y lo cierto es que nuestra jurisprudencia contiene casos que realmente generan la duda sobre si ha habido o no captación de la voluntad del causante y que, por lo general, finalizan con la validez del testamento.

La SAP Ourense 30.1.2002 ${ }^{79}$ trata del testamento otorgado por persona de 94 años que modifica una anterior hijuela en que procedía a una partición igualitaria para sus hijas atribuyendo todo el bien en cuestión solo a una de ellas, aquella que la atendía. Argumenta la sentencia que "no se pone en duda, pese a su avanzada edad, la capacidad de $\mathrm{D}^{\mathrm{a}}$ Carmen Iglesias para otorgar el debatido testamento. El Notario autorizante, que la visitó dos veces una para hablar con ella y otra para el acto formal de otorgamiento en presencia de los testigos según refiere la actora en confesión, la estimó apta, intelectual y psíquica-

77 Para una vision crítica de este precepto, véase David Horton, "The Uneasy Case for California's Care Custodian Statute", 12 Chapman University Law Review, 2008, p. 47 ss. Este rol del attorney como "Evaluation Official" es el que desempeña en Cataluña el notario, ya que interviene con funciones fiscalizadoras de la posible captación de la voluntad del testador. Al respecto, Irene D. Johnson, "Preventing Identity Theft and Other Financial Abuses Perpetrated Against Vulnerable Members of Society: Keeping the Horse in the Barn Rather than Litigating over the Cause and/or Consequences of His Leaving", 79 University of Missouri-Kansas City Law Review, 2010, p. 99 ss, en particular p. 115.

78 Cabe traer a colación la SAP Valencia, sec. 11, 15.6.2011, JUR 392630, en un caso de persona mayor que testa a favor de su asistenta modificando el testamento anterior favorable a su primo, que razona así: "en los testamentos ha de primar la voluntad de la testadora, que siempre es prevalente (...), y la voluntad reflejada por la testadora en el testamento que se cuestiona es designar como heredera universal a la hoy demandada, bien fuera ello porque en su vejez y decadencia física se viera asistida, retribuida o no, por la Sra. Luz, bien porque, al contrario, en esos momentos de necesidad se viera desasistida y desamparada por quién había nombrado heredero cuatro años antes. En cualquier caso, frente a la presunción de capacidad de la causante, corroborada por la certidumbre de capacidad que da el Notario autorizante, tendría que haber sido el demandante, en cuanto impugnante del testamento, quién debería haber acreditado, con prueba evidente, completa e inequívoca, la merma intelectiva y volitiva que dice presentaba la Sra. Adelaida al tiempo de otorgar el testamento, y la captación de voluntad que afirma realizó sobre ella la demandada para obtener con malicia el otorgamiento de un testamento a su favor".

79 AC 663. 
mente, para ello. La prueba testifical recibida a instancia de la demandante, en un total de diez personas especialmente cercanas a la testadora o familiares (entre ellos doña Pura G., que la cuidó en los años de enfermedad, don Manuel A. B. y su esposa doña Aurora M., tíos de ambas litigantes, doña Carmen A. B., prima carnal de los dos hermanas) afirman que la referida causante estuvo siempre lúcida, describiéndola como especialmente lúcida que sorprendía por su capacidad mental, ingenio, de excelente memoria, muy conversadora y perfectamente conocedora tanto de lo que ocurría alrededor o de lo que quería. Estos son hechos ciertos, sin que quepa hacer supuesto de la cuestión, como hace el Juzgador «a quo» sobre la genérica vulnerabilidad emotiva de una persona de avanzada edad, es en el caso concreto y particular en donde habrán de analizarse las circunstancias específicas que concurren en la vida de cada testador para poder pronunciarse sobre si su voluntad decisoria está o no viciada o lo que es lo mismo si su liberalidad testamentaria vino determinada por un falso conocimiento de la realidad que le fue provocado por el heredero beneficiado. El hecho de que doña Carmen I. P. contase con 94 años de edad cuando Notario otorgó testamento y al que le fuere presentada minuta escrita sobre su última voluntad, no puede entenderse en sí mismo que aporte indicios de un consentimiento erróneo por dolo, como tampoco cabe tildar de especial complejidad jurídica las capitulaciones integrantes del testamento en cuestión, sino que objetivamente son perfectamente comprensibles para una persona de capacidad intelectiva normal y así hubo de considerarlo el fedatario autorizante al comprobar la espontaneidad de su voluntad dispositiva. No existe ni una sola prueba que apunte a que doña Carmen fuese persona de personalidad débil o tornadiza, susceptible de ser sometida su conciencia a la voluntad de otro". Tampoco se concede relevancia a un acta notarial de la hija apartada en que manifestaba su disposición a cuidar de su madre y que su hermana no se lo permitía, pues la cuidadora manifestó que cuando estaba ella sola por las mañanas con la causante esa hija tampoco la visitaba. Y concluye la sentencia: "demostrada la normalidad psíquica de la testadora, la prueba de la existencia de dolo determinante de la falsedad en la causa habría de ser concluyente aunque fuera por vía indirecta o de presunciones, que es algo más que la subjetiva sospecha. El dolo no se presume sino que ha de ser debidamente probado". En definitiva, hay suficiente capacidad natural, el testamento no es especialmente complejo y el cambio en el testamento aparece justificado por ser la beneficiaria la hija que cuidaba a la testadora.

La sentencia de la misma audiencia, ya mencionada, de 29.12.2004 ofrece un caso ciertamente comprometido. Ingresado en el hospital, el testador otorga un nuevo testamento revocatorio del anterior en que, en vez de instituir herederos por partes iguales a sus dos hijos, instituye únicamente a uno y al otro le lega la legítima estricta. La sentencia relata que el notario le reprochó lo discriminatorio que resultaría el dejar sólo a uno la mitad de la legítima estricta y el resto al otro, que si lo deseaba podría pensarlo mejor, etc., insistiendo el tes- 
tador en que ello era lo que deseaba. A la vez, subraya que "el demandado es el que procede a buscar un notario a los efectos de que su padre otorgue nuevo testamento hecho que tiene lugar un día en que le corresponde por turno acompañarlo, pero manifiesta que lo hizo a petición de su padre, y tal circunstancia se la corrobora éste al Notario autorizante, insistiendo reiteradamente en su deseo de otorgar testamento en los términos recogidos. Aunque el demandado niega que conociera el contenido de la disposición testamentaria controvertida, muy probablemente tal afirmación no responda a la verdad. En tal sentido, el hecho de no aceptar el ofrecimiento de empleados de Caixa Galicia de poder retirar de la cuenta, cuando se produjo el óbito de su padre, y de acuerdo con su hermano, la mitad de la cuenta, que es lo que supuestamente le correspondería a cada uno de ellos, evitándose así el pago de impuestos sucesorios, es claro indicio de que sabía que le correspondía mucho más de dicha mitad, o, al menos, se lo suponía; pero ello, evidentemente, podrá ser todo lo reprochable que se quiera en el orden moral, pero en sí mismo no evidencia una actuación previa constitutiva de dolo o fraude. Algo semejante puede decirse de la extraña transferencia del padre a favor del demandado, quien encarga a la gestoría Casal la tramitación de la transferencia del vehículo uno o dos días antes del fallecimiento del testador, declarando el demandado que le pagó en metálico. Al respecto, cabe afirmar que en absoluto se prueba el pago del precio, puesto que aunque éste se hubiera hecho en metálico, hecho insólito e inverosímil dado el estado del enfermo, es claro que existen múltiples formas de acreditar su pago, lo que no se hizo". Este relato fáctico demostrativo de la ausencia de motivos para reducir la participación de uno de los hijos a la legítima estricta no es suficiente para entender acreditado el dolo: "no se estima probada la concurrencia de una maquinación dolosa de éste que implicara captación o sugestión de la voluntad paterna, ni indicios de violencia o intimidación determinantes de una situación de temor en el padre que le hubiera inducido a cambiar disposiciones testamentarias precedentes". El tribunal pone el énfasis en la libertad de testar: "Uno de los dogmas fundamentales del derecho sucesorio es el de la primacía de la voluntad del testador, en tanto en cuanto es titular exclusivo de la facultad de disponer libremente de sus bienes, con la única obligación de respetar los derechos de los legitimarios. En definitiva, el causante es soberano para disponer, después de su muerte, de su patrimonio según estime conveniente". Con todo, quizá los magistrados no debieron quedar satisfechos ante el hecho de la intervención del hijo en el otorgamiento del testamento -ya sabemos que en el derecho norteamericano este elemento sería determinante de la undue influence- $\mathrm{y}$, por ello, decidieron no hacer imposición de costas pese a la desestimación.

LA SAP Málaga 10.2.2005 ${ }^{80}$ no estima la existencia de dolo en la modificación del testamento instituyendo como única heredera solo a una de las institui- 
das en el anterior al hallar una explicación pata tal cambio: "concurren en las actuaciones una serie de factores que contribuyen a justificar el cambio de las disposiciones testamentarias, pasando de ser dos las instituidas como herederas a solamente una de ellas, la ahora demandada apelada, ya que ésta es la persona que convivió con la testadora en su propio domicilio durante bastante tiempo, en tanto que la actora, por el contrario, había perdido todo contacto con la misma en un período dilatado de nueve meses, siendo de resaltar, por otro lado, que la expresión «fraude» que se utiliza en el artículo 673 del Código Civil citado como vulnerado por la recurrente, según doctrina mayoritaria, responde junto con el «dolo» a matices de un mismo vicio de consentimiento, con fundamental sinonimia, siendo incluibles ambas manifestaciones en la fórmula del artículo 1268, consistiendo, en definitiva, en palabras o maquinaciones insidiosas mediante las cuales es inducida una persona a otorgar el testamento que sin ellas no habría dispuesto, o bien con el artificio o empleado para impedir al causante la libre testamentificación, vicios del consentimiento que, como se viene diciendo, no son de apreciar en el caso en atención a las circunstancias hasta aquí analizadas, ya que, al igual que sucede con la negociación contractual, el dolo o fraude requiere una prueba cabal y cumplida de su existencia, sin que basten meras presunciones, a lo que debemos añadir que la edad avanzada de la causante testadora no es por sí sola causa determinante de su falta de capacidad". De nuevo la concurrencia de una razón explicativa de la modificación del testamento resulta un elemento clave de la resolución judicial.

La también citada anteriormente SAP Coruña 18.3.2009 se ocupa de otro caso de revocación de testamento con reparto igualitario por uno en que una de las hijas es tratada de forma desigual. La sentencia analiza cuidadosamente los hechos y, aparte de señalar que la testadora iba mutando su testamento en función de las relaciones que mantenía con sus hijos, y recalcar su capacidad testamentaria y de decisión, encuentra una justificación al contenido testamentario, cual es que la hija "al conocer el contenido del testamento otorgado por su madre en Pontedeume que la finca y casa de La Graña no iba a ser para ella, decidiese levantar el cierre de la finca de su propiedad en la colindancia con la de su madre, lo que produjo un profundo disgusto de la madre, (...), y así reconoce abiertamente su enemistad y alejamiento de su hija en el acto del juicio de la acción de tutela sumaria de la posesión, sin que se aprecie personalidad débil susceptible de ser sometida su conciencia a la voluntad de otro", por lo que no se entiende acreditado que concurra "prueba plena de la existencia de artificios dirigidos por terceros para desviar la libre determinación de las decisiones de la testadora de tal importancia o calibre que sean perturbadores de la libertad y plena autonomía de efectuar sus disposiciones de última voluntad". 
De nuevo el reparto desigual, con dos hijas a quien se atribuye la legítima estricta, conforma el supuesto de hecho de la SAP Ávila 13.12.2012.81 Tras la consabida definición del dolo testamentario ("maniobras o artificios que llegan a anular la voluntad del testador, como pueden ser la sugestión y la captación, entendida como una modalidad del dolo causal dirigido a excluir a una persona de la sucesión; o bien que se consiga desviar la voluntad del testador, haciéndole testar en un sentido distinto y como lo hubiera hecho sin intervenir el artificio"), la sentencia lapidariamente se limita a afirmar que no hay prueba del dolo. De manera semejante, la SAP Vizcaya 24.2.2002 ${ }^{82}$ había rechazado la alegación de la "captación o influencia" por parte de la segunda esposa del testador, sin realizar especial hincapié en la cuestión.

En la antes citada SAP Álava 5.7.2012, el testador es una persona soltera cuyos únicos parientes son un hermano que vivía en Barcelona y dos hermanos residentes en Vitoria con los que no mantenía relación. En su testamento, además de la familia de Barcelona, beneficiaba a una persona extraña, que la demandante de nulidad del testamento afirmaba que se dedicaba a sugestionar personas ancianas. La documental médica no revela ningún trastorno psíquico, sino alguien bien orientado y capaz de conversar abiertamente. Tampoco consta que la familia de Barcelona lo acompañara cuando acudió a la notaría para testar, por lo que no se aprecia ningún motivo para declarar la nulidad del testamento.

El supuesto de hecho de hecho de la SAP Madrid 14.2.2013 ${ }^{83}$ viene configurado por el matrimonio en 2008 de la causante tras serle diagnosticado un cáncer de pulmón y el otorgamiento posterior de testamento y de diversas donaciones al marido en detrimento de la hija. La sentencia pone el énfasis en "la conformidad a derecho tanto del testamento como formalmente las donaciones efectuadas, y la inexistencia de prueba alguna de que la causante sufriese, más allá de la influencia anímica por el diagnóstico llevado a cabo, un deterioro psíquico que afectase a su capacidad volitiva o cognitiva en orden a viciar de manera significativa su consentimiento en las operaciones llevadas a efecto. Tal y como pone de relieve la sentencia combatida, de las pruebas testificales practicadas no se desprende que, más allá de un comportamiento calificado como raro o sorprendente, existiese ese deterioro psíquico de suficiente entidad, y no cabe deducir sin más, como pretende la demandante, que los acontecimientos producidos fueron impulsados por la actividad desplegada por la actora tendente a su propio exclusivo beneficio en detrimento de los derechos de la demandante". Subyace latente nuevamente la concurrencia de un motivo justificador del testamento, cual es el matrimonio de la causante y, cabe deducir, la mala relación de la hija con el nuevo consorte. 
La SAP Coruña 2.3.2012 ${ }^{84}$ contempla el supuesto de los testamentos otorgados por un matrimonio en que se desheredaba a la hija adoptiva -incluso se intentó más tarde la declaración de nulidad de la inscripción marginal de adopción por no haberse completado esta- e instituyendo a un sobrino de la esposa. Ante la alegación de la captación de la voluntad por el sobrino, la respuesta de la sentencia es contundente: "Los causantes no mantenían relación alguna con su hija adoptiva desde hacía más de 30 años, pese a que vivían cerca. No los atendió para nada en su ancianidad. Tuvo que hacerse cargo don Conrado. Hasta el punto de que es él quien los atiende, los lleva al hospital, permanece con ellos cuando están ingresados, y finalmente pasan los últimos años en su casa y bajo sus cuidados. Es más, doña María Cristina reconoció que ni se había enterado de cuándo habían fallecido". Para el tribunal, es perfectamente explicable, por razones de confidencialidad, que los testamentos se otorgaran en notaría de localidad distinta de la de su residencia, y la pretendida prueba testifical se califica de "meras expresiones de dudas malintencionadas por una endémica desconfianza".

En la SAP Barcelona, secc. 19, 22.3.2012, de nuevo una hija es desheredada a favor de su hermano. Aunque se alega la posible captación de voluntad por tratarse de una persona vulnerable, con algunos déficits en sus funciones cognitivas, la sentencia de desarrolla por el cauce de la capacidad testamentaria y no halla motivos suficientes para la anulación del testamento. Por otra parte, encuentra una justificación a la mutación de la voluntad de la causante, que en dos años otorgó hasta tres testamentos, por las desavenencias surgidas con su hija, que esta incluso llegó a airear en un programa de televisión.

Un supuesto similar es el de la SAP Toledo 20.5.2013. ${ }^{85}$ Los causantes convivían con la hija beneficiada en el testamento y otorgaron el testamento en casa, principal argumento de la presencia de dolo. La sentencia rechaza la captación de voluntad, manifestando que una tal percepción conduciría a la nulidad de los testamentos de personas ancianas que convivan con uno de sus hijos al que por agradecimiento, por cariño o por un sentimiento subjetivo de justicia deciden premiar en su herencia, todo ello cuando la Ley no limita la edad para testar ni obliga a beneficiar a todos los hijos por igual, a salvo legitimas. Además, se hace un esfuerzo por delimitar el dolo invalidante del testamento: "para que dicho dolo pueda determinar la nulidad del testamento, que sea calificable de dolo grave en su aptitud para desviar la voluntad del otorgante, excluyéndose las acciones capaces de ganarse la voluntad del testador como el cuidado o atención especial al mismo o comportamientos cariñosos. Es preciso por ultimo para que el testamento pueda considerarse nulo y viciada la disposición testamentaria que la voluntad del otorgante emitida sin la natural libertad lo sea precisamente por causa de la influencia 
insidiosa. En el concepto reseñado caben toda serie de astucias dirigidas a conseguir tal resultado si bien este dolo no opera sino mediante el ejercicio de la acción específica dirigida a su declaración, que no puede prosperar sin una cumplida prueba por parte de quien alegue la concurrencia del dolo, pues el principio favor testamenti supone la presunción de validez del testamento otorgado que solo puede desvirtuarse por prueba rotunda y contundente". Entre líneas puede inferirse que hay una justificación, siquiera subjetiva, para la modificación del testamento anterior con reparto igualitario entre los hijos, lo que impide apreciar la concurrencia de dolo, más aun cuando no hay discusión sobre la capacidad testamentaria.

La testadora de la SAP Barcelona 17.5.201086 presentaba, además de una edad avanzada, una salud frágil, pese a lo cual fue conducida por la demandante y principal beneficiada en el testamento anterior al pueblo donde solía pasar los veranos y en que residían también los demandados, que contrataron una cuidadora para la causante y que resultaron agraciados con el grueso de la herencia en un testamento notarial otorgado ese verano. El hecho de que fuera acompañada al pueblo por la demandante es un factor clave para el tribunal: "desdibuja el dolo denunciado, toda vez que no fueron los demandados quienes atrajeron a la causante al pueblo y el hecho que la visitaran frecuentemente, como en otras ocasiones, no hace presumir la existencia de maquinación alguna. Incluso si en las visitas, a pesar de no haberse probado por la incomparecencia de la cuidadora, ésta era invitada a salir de la habitación, la conclusión sería la misma, toda vez que cualquier persona tiene derecho a su intimidad".

Un caso en que la alegación de dolo captatorio se vuelve contra quien lo alega lo proporciona la SAP Baleares 9.11.2010.87 La pericial manifiesta que la testadora era efectivamente susceptible de ser influenciada, pero advierte la sentencia que "el perito se limita a enunciar una hipótesis y, por lo demás, no se sabe si el testamento, en el que favorece a su sobrina demandada, fue fruto de la influencia de ésta o, más bien, reacción frente a la influencia sobre su voluntad pretendida por el sobrino actor. Así, en el interrogatorio de parte la codemandada doña Teodora, quien durante veintitrés años fue la sirvienta de la testadora, manifestó que era su sobrino Carlos Miguel, el hoy actor, quien le llevaba las cuentas, que le acompañó varias veces a la notaría, que Carlos Miguel nunca estaba conforme y discutía con su tía y le gritaba, y que incluso le amenazó con que no iría al cielo, lo que provocó en doña Crescencia gran desazón que le llevó a hacer una consulta al respecto a su confesor". Por consiguiente, la impugnación es desestimada. 
La testadora de la SAP Valencia 26.11.2011 ${ }^{88}$ revocó su testamento en que instituía a su hija, desheredándola y nombrando heredero a un conocido que la visitaba con frecuencia, y que la sentencia indica que era testigo de Jehová. Nuevamente se desestima la demanda, porque no se induce, "al no haber presencia personal de los testigos de ello, maquinación alguna del demandado para hacer cambiar las relaciones de la actora con su madre ni para que ésta por ello cambiara su inicial testamento del año 2002, en la medida de que esas relaciones materno-filiales no buenas desde antiguo las reconoció dicha actora y, si bien pudieron empeorar a raíz de iniciar los cuidados de la misma dicho demandado y en el curso de éstos también hubo momentos de empeoramiento de las de éste con la causante que le llevaron a denunciarlo sin condena alguna, ello no supone la realidad de hechos o cadena de hechos que al unísono envuelvan esa maquinación intencionadamente dirigida a mover en determinado sentido la voluntad del testador". Se trata de una distribución de riqueza que podríamos denominar "no natural" al beneficiar a un extraño, además, y como nota expresamente la sentencia, con un tinte religioso, y sin embargo no se cuestiona la validez del testamento.

Hay también alguna sentencia en que la beneficiada por el testamento es la cuidadora. Merece especial atención la SAP Alicante 30.5.2012. ${ }^{89}$ La testadora, que vivía sola y había testado a favor de su hermano, acudió a los servicios sociales de su ayuntamiento para que le proporcionaran una cuidadora. Se reconoce en la sentencia que "[c|iertamente resulta extraño a la Sala que en el periodo comprendido entre el 18 de agosto de 2010, fecha en la que el Ayuntamiento de la localidad de Jávea designa a la asistente social, la demandada Doña Inés para la atención de Doña María Antonieta, hasta el fallecimiento de ésta en 24 de septiembre de 2010, poco más de un mes, la citada Sra. María Antonieta cambiara el testamento que había hecho en fecha 26 de mayo de 2009 en el que legaba a su hermano, el demandante. En este último testamento, "lega a Doña Inés, nacida el (...) de 1975 en Palmira Valle (Colombia) todos los bienes, derechos y acciones quela testadora tenga en España, bajo la condición que la cuide y asista hasta el momento de su fallecimiento". Entre los motivos de la impugnación se cuenta la existencia de dolo destinado a captar la voluntad de la causante. La sentencia solo entiende probado que la cuidadora empezó trabajando tres horas por semana pero fue aumentando su presencia hasta quedarse a dormir, y aunque a veces la sustituía su hija y a pesar de alguna declaración testifical en el sentido de que quizá no estaba suficientemente bien atendida, y tiene por acreditado el cumplimiento de la condición, sin que considere que hay prueba ni tan solo indiciaria de dolo. El conflicto se plantea, pues, entre un hermano y una extraña; no parece que con el hermano existiera una relación muy intensa, puesto que la testadora acudió

88 JUR 2013160221.

89 Id Cendoj: 03014370062012100279. 
a los servicios sociales públicos para procurar su cuidado, pero por otro lado se testa a favor de una persona a la que se conocía desde tan solo hacía un mes.

Hasta ahora solo se han reportado sentencias que desestiman las demandas de nulidad del testamento negando la existencia de dolo. En sentido contrario cabe destacar la SAP Sevilla 14.2.2005, ${ }^{90}$ que sí entiende acreditada la captación de la voluntad de la testadora por el hijo beneficiado en el testamento. La prueba parece en verdad contundente: "La empleada doméstica Doña Paula, con asistencia diaria en la casa de Doña Mariana, atestiguó que la misma consumía, prácticamente, una botella diaria de ginebra, que se compraba por cajas, y que padecía de alucinaciones, en cuanto decía ver a personas difuntas y que, con igual ignorancia del testamento, había oído a Doña Mariana que de puertas adentro era para Raquel. Con igual desconocimiento del contenido del testamento testifica Doña María Rosario, amiga y visitante asidua de Doña Mariana en el sentido de que ésta se encontraba dominada por su hijo Don José Pablo, de cuyo testamento sí conocía que se difería en veinte años. El administrativo Don Manuel, con igual adveración del referido consumo alcohólico, manifestó que el testamento fue una sorpresa para todos porque Doña Mariana pregonó siempre la igualdad entre sus hijos y, el conductor Don José Augusto, reiterando lo anterior dijo que era el encargado de comprar la Ginebra, con el consumo de una botella diaria y que Don José Pablo tenía atemorizada a su madre y hablaba de testamentos en el sentido de que hasta veinte años no se cogería nada. Por último el vecino de planta Don Juan Ignacio, testifica que Don José Pablo controlaba las visitas de su madre Doña Mariana y le comentó que él y su madre habían hecho un testamento "sibilino". Además, el médico personal corroboró el alcoholismo. La sentencia no menciona la palabra "dolo", aunque reconoce la captación de la voluntad y la ausencia de suficiente capacidad natural por el alcoholismo crónico y su afectación de las capacidades volitivas e intelectivas de la testadora.

Puede concluirse, a la vista de las anteriores sentencias, lo siguiente:

Cuando el conflicto se plantea entre quienes son legitimarios -el causante otorga un testamento que rompe la repartición igualitaria de la legítima para beneficiar más o en exclusiva a uno de sus descendientes-, el tribunal queda satisfecho y no estima la concurrencia de captación de la voluntad testamentaria si halla una justificación a la revocación del testamento, sea en forma de malas relaciones con el hijo o hija apartados, sea porque el beneficiado ha cuidado al causante en su última enfermedad, etc. Si no se aporta esa justificación, la sentencia puede ser estimatoria. Cuando las personas en conflicto no son legitimarios - por ejemplo, sobrinos, hermano y cuidadora- los tribuna- 
les españoles suelen conceder primacía a la voluntad testamentaria expresada en el testamento, aunque el testamento presente dudas en atención a las circunstancias concurrentes.

El panorama, tras el análisis de las sentencias españolas que han abordado el tema, es completamente opuesto al norteamericano. Puede afirmarse que la anulación de un testamento basada exclusivamente en el dolo -o, lo que es lo mismo, en la sugestión o captación de la voluntad de un testador vulnerable- es harto improbable, salvo que se trate de un abogado, si tomamos como referencia la SAP Lleida 4.4.2013 con que se ha iniciado este capítulo, por lo que parece, o que suscite un conflicto entre legitimarios sin que concurra una razón explicativa suficiente a juicio del tribunal para el trato desigual deparado por el causante. ${ }^{91}$ Sobre la base de la intimidación apenas puede computarse un par de sentencias. Mejor suerte ha merecido la vía de la falta de capacidad de obrar, pero siempre que esta sea notoria, es decir, o bien con un alcoholismo grave cercenador de la capacidad volitiva, o con enfermedades que provocan una pérdida sensible de facultades intelectuales. Lo que parece evidente es que la demanda impugnadora tiene mayores posibilidades de éxito si se combinan varios elementos: el incumplimiento, ni que se parcial, de alguna solemnidad con síntomas de merma en la capacidad natural suele terminar en una estimación de la nulidad. Los tribunales españoles tienden a decantarse por la eficacia del testamento, tal vez por el peso de la idea del favor testamenti. Como punto de partida, no es criticable, y de hecho el fallo de la mayoría de sentencias es razonable. En efecto, parece preferible, ante la duda, inclinarse por la eficacia del testamento, pues este enfoque es el más respetuoso con la libertad de testar, incluso aunque alguna vez pueda existir el temor de que quien ha captado la voluntad de un testador vulnerable se lleve el premio de la herencia. La sentencia del Hoge Raad de 10.12.2010 relativa al art. 4:953 del viejo Código civil neerlandés en un caso en que se debatía si la inhabilidad para suceder antes examinada afectaba a un médico, reprochó a la sentencia de instancia que protegía más la libertad de testar en abstracto que al paciente/testador del caso en cuestión, ${ }^{92}$ y el mismo reproche podría formularse a alguna de las sentencias de nuestra jurisprudencia que antes se han mencionado. Como ya se ha dicho en otro lugar de este libro, el papel del notario es fundamental, pues él puede detectar si el testador está sometido a alguna presión o sugestión; una entrevista a solas con preguntas sobre el contenido de su testamento y las razones de ese contenido pueden aflorar la existencia de una voluntad captada. Los tribunales norteamericanos, en cambio, en un sistema sin legítima a favor de los descendientes, son mucho

91 También en los países de common law donde la undue influence es de interpretación menos extensiva (Inglaterra o Nueva Zelanda) es difícil que se anule un testamento por esta causa cuando el favorecido es un hijo que estaba viviendo al causante, salvo que concurra coacción; véase Sloan, Informal Carers, p. 225 ss, y Gary M. Harrison, "Undue Influence. An Issue of Presumption", NZ Lawyer, 2010, nº 141.

92 "Ten onrechteheeft het hof dus de bescherming van de testeervrijheid als ratio van die bepaling vooropgesteld, in plaats van de bescherming van de patiënt/testateur", tomada de la transcripción de A.J.M. Nuytinck, "Lijdenaan het leven", Ars Aequi, n 60, 2011, p. 131 ss. 
más proclives al reparto igualitario y a que los bienes queden para la familia; podría decirse que por la vía de la impugnación del testamento por undue influence garantizan la legítima en un sistema que la desconoce. En todo caso, lo que sí ha quedado meridianamente claro es que los derechos civiles españoles disponen de suficientes resortes para proteger al testador vulnerable, y que los tribunales se muestran dispuestos a aplicar dichos mecanismos en los casos que deben dilucidar. Y este es un resultado mucho más venturoso que el que ofrece el derecho norteamericano, que aparenta ser el paradigma de la libertad de testar pero que, sin embargo, en realidad la coarta con pronunciamientos con frecuencia más morales que jurídicos como ha denunciado la doctrina de aquel país. 